\begin{tabular}{|c|l|}
\hline Title & Onsite survey on the mechanism of passive aeration and air flow path in a semi-aerobic landfill \\
\hline Author(s) & Matsuto, Toshihiko; Zhang, X in; Matsuo, Takay uki; Y amada, Shuhei \\
\hline Citation & $\begin{array}{l}\text { Waste Management, 36, 204.212 } \\
\text { https://doi.org/L0.1016j.wasman.2014.11.007 }\end{array}$ \\
\hline Issue Date & 2015-02 \\
\hline Doc URL & http://hdl.handle.net/2115/58483 \\
\hline Type & article(author version) \\
\hline File Information & Waste Manage_36_2015.pdf \\
\hline
\end{tabular}

Instructions for use 


\title{
Onsite survey on the mechanism of passive aeration and air flow path in a semi-aerobic landfill
}

\author{
Toshihiko Matsuto*, Xin Zhang, Takayuki Matsuo, Shuhei Yamada
}

Laboratory of Solid Waste Disposal Engineering

Faculty of Engineering, Hokkaido University

Kita 13, Nishi 8, Kita-ku, Sapporo, Hokkaido 060-8628, Japan

*Corresponding author: Toshihiko Matsuto

Tel \& Fax: +81-11-706-6825, E-mail: matsuto@eng.hokudai.ac.jp

\section{Abstract}

The semi-aerobic landfill is a widely accepted landfill concept in Japan because it promotes stabilization of leachates and waste via passive aeration without using any type of mechanical equipment. Ambient air is thought to be supplied to the landfill through a perforated pipe network made of leachate collection pipe laid along the bottom and a vertically erected gas vent. However, its underlying air flow path and driving forces are unclear because empirical data from real-world landfills is inadequate. The objective of this study is to establish scientific evidence about the aeration mechanisms and air flow path by an on-site survey of a full-scale, semi-aerobic landfill.

First, all passive vents located in the landfill were monitored with respect to temperature level and gas velocity in different seasons. We found a linear correlation between the outflow rate and gas temperature, suggesting that air flow is driven by a buoyancy force caused by the temperature difference between waste in the landfill and the ambient temperature. Some vents located near the landfill bottom acted as air inflow vents. Second, we conducted a tracer test to determine the air flow path between two vents, by injecting tracer gas from an air sucking vent. The resulting slowly increasing gas concentration at the neighboring vent suggested that fresh air flow passes through the waste layer toward the gas vents from leachate collection pipes, as well as directly flowing through the pipe network. Third, we monitored the temperature of gas flowing out of a vent at night. Since the temperature drop of the gas was much smaller than that of the environment, the air collected at the gas vents was estimated to flow mostly through the waste layer, i.e., the semi-aerobic landfill has considerable aeration ability under the appropriate conditions. 


\section{Background}

In recent years, landfill aeration has been considered to be one of the most important options for the concept of sustainable landfill. While bioreactor landfills and thermal/biological pretreatment are other options for landfill operation, landfill aeration is mainly used in old landfills to "convert conventional anaerobic landfills into a biological stabilized state” (Ritzkowski and Stegmann, 2012). Studies on landfill aeration appeared in the late 1990s. Leikam et al. (1997) and Heyer et al. (1999) reported on leachate quality, gas generation, and temperature build-up for the in situ aeration of an old landfill in Germany. Raga and Cossu (2014) also carried out in situ aeration to reduce biogas and leachate generation in Italy. In 2004, the Landfill Aeration Task Group was established by the International Waste Working Group (IWWG), and subsequently published a monograph "Landfill Aeration in 2007" (Stegmann and Ritzkowski, 2007).

The semi-aerobic landfill, proposed by Hanashima in the 1970s, was categorized as an “aerobic landfill” by Ritzkowski and Stegmann (2012), but it uses no mechanical equipment for aeration. The key concept of a semi-aerobic landfill is the connection of a leachate collection pipe with gas vents that directly connect to the atmosphere (Figure 1). According to Matsufuji (1998), this idea was first developed in the early 1970s when the biochemical oxygen demand (BOD) in leachate from an anaerobic landfill, which was used as a reference for evaluating the effect of forced aeration, was found to be as low as that in aerobic landfills. Hanashima suggested that the BOD in the leachate was lowered by the air supplied from the leachate collection pipe, which was directly connected to the atmosphere. At this point, only the leachate collection pipe was considered as an air supply source. However, as the depth of the waste layer increased as landfill works proceeded, air supply capacity was limited by the low permeability of the dumped waste load and by the increased distance from the leachate collection pipe. Therefore, due to the increase in the depth of the waste layer, the air supply pipe was extended by the construction of vertical gas vents that were connected to the leachate collection pipe.

Unlike aerobic landfills with forced injection or extraction, in which the flow paths of air and gas can be estimated as a physical process, the air and gas flows in a semi-aerobic landfill have simply been assumed. Figure 1 shows an assumed air flow in semi-aerobic landfills, i.e., air flows into the waste layer both from the leachate collection pipe and from the gas vents, as indicated by the arrows in the figure. This 
assumption is naturally derived from the idea to extend the leachate collection pipe in the vertical direction as mentioned above. The driving force of air flow in semi-aerobic landfills is considered to be the buoyancy force caused by temperature differences between the waste in the landfill and the atmosphere. Matsufuji and Tachifuji (2007) explained that air and gas, warmed by the heat generated during the aerobic biodegradation of waste, tend to rise and get vented through the gas vents. Therefore, the negative pressure produces a siphoning effect that draws ambient air into the leachate collection pipe. The direction of air flow around the gas vents shown in Figure 1 is somewhat contradictory to this statement by Matsufuji.

There have been numerous studies on semi-aerobic landfills in Japan in the past half century (Park et al.(1997), Hirata et al.(2012), for example). These studies were mostly conducted using a cylindrical lysimeter packed with various types of waste, in which semi-aerobic conditions were realized by opening the bottom and the top of the lysimeter to expose the waste to the atmosphere. An anaerobic lysimeter that was closed at both ends was usually used as a control. In most studies, the leachate was the main concern with respect to environmental pollution, and gas was monitored only for the sake of determining the mass balance of carbon.

On the other hand, few studies have been conducted on a full-scale, semi-aerobic landfill, especially with regard to aeration. Yanase et al. (2010) measured the air flow rate into the leachate collection pipe during different seasons of the year. They showed that the air flow rate negatively correlated with the ambient temperature: a large flow rate occurred in winter and there was no air flow in summer. This fact supports Matsufuji and Tachifuji's (2007) assumption that the driving force of air flow is the temperature difference. By measuring increases in the air and gas flows in the gas vents, Kim et al. (2010) showed that air and gas did in fact flow into the gas vents from waste layer. Although the study was conducted in a landfill where gas vents were constructed after the closure of the landfill, and they were not connected to the leachate collection pipe, an air flow through the waste toward the gas vents had been expected in this semi-aerobic landfill. Yanase (unpublished data, 2004) recorded the temperature of waste and gas emitted from a gas vent continuously for a year at the same landfill, as in Yanase et al. (2010). Two temperature sensors were located $3 \mathrm{~m}$ away from each other at a depth of $3 \mathrm{~m}$, and these two temperatures were exactly the same except for short term fluctuations in the gas temperature. Combining the results of these latter two studies, we can assume that air flows through the waste layer, and warm air collects at gas vents. 
These few studies of full-scale landfills give only fragmented information about aeration in semi-aerobic landfills. For example, Yanase et al.(2010) did not measure the gas flow rate at gas vents, and Kim et al. (2010) surveyed only a few gas vents. There is inadequate data on the overall aeration process in landfills. Therefore, based on the assumption made by Matsufuji and Tachifuji (2007), this study aims to establish scientific evidence for the aeration mechanisms and air flow path by the on-site survey of a full-scale, semi-aerobic landfill.

\section{Surveyed landfill and methodology}

\subsection{Description of the landfill}

This study was conducted at an industrial solid-waste landfill in Sendai, Japan, which started operations in November 2003. There are two zones, with a total area of $78,241 \mathrm{~m}^{2}$ and a volume of $2.1 \times 10^{6} \mathrm{~m}^{3}$. The second zone, in which our on-site study was conducted, started receiving waste in November 2009. A typical waste layer is 2.5 m thick and covered daily by a 10- to 20-cm-thick soil layer. In June 2013, there were eight waste layers, and the total thickness of the landfill was about $25 \mathrm{~m}$, including 30-50 cm of intermediate cover. The waste composition on a weight basis is as follows: waste plastics (28\%), demolition waste (20\%), waste metals (8\%), incineration residues (7\%), and sludge (12\%) which is the main source of organic materials. The other $25 \%$ consists of mostly incombustible waste, such as pretreated waste and ash.

Figure 2 shows the layout of the leachate collection pipes and the passive gas vents, indicated by the solid line and symbols. The main leachate collection pipe ends in an open leachate collection pit. All gas vents are connected to the leachate collection pipes, a common practice in semi-aerobic landfills. Typically, vertical gas vents are constructed on top of the main leachate collection pipe, and secondary leachate collection pipes are used as inclined gas vents that branch out toward the peripheral area of the landfill. In this landfill, as shown in the cross-section view No. 7-N8-PN14 in Figure 2, vertical gas vents are also located at the bent parts of the leachate collection pipes, for example N1-N9. As a result, there are three types of gas vents, which are indicated by different symbols and identified using the following numbers:

$$
\text { No. 1-9: }
$$

N1-N9, S1-S7:

PN1-PN16, PS1-PS17: gas vents on the open end of the branching leachate gas vents on the main leachate collection pipe gas vents on the bends of the branching leachate collection pipes 
collection pipes.

145 The diameter of the gas vents is $30 \mathrm{~cm}$ (inner diameter is $28 \mathrm{~cm}$ ), except for vent No. 1, 146 which is $60 \mathrm{~cm}$ in diameter. The diameter of the main leachate collection pipe is $60 \mathrm{~cm}$; 147 the length from vent No. 1 to No. 9 is approximately $280 \mathrm{~m}$ (Nos. 1-3: 70 m, Nos. 3-6: $148110 \mathrm{~m}$, Nos. 6-9: $100 \mathrm{~m}$ ). The intervals between the gas vents are in the range of 15 to 14935 meters. Both the leachate collection pipes and the gas vents are perforated.

\subsection{Survey method}

(1) Survey schedule

We visited the site on three occasions-on June 18 and 19, October 24 and 25, and November 15 and 16, 2013. In June, all gas vents were identified and numbered, as shown in Figure 2, and we determined the gas velocity and temperature at the exits of all gas vents. The composition of gas exiting the vents was measured at those vents from which the gas flow rate was relatively high. In October, we determined the altitudes of the gas vents, and the gas flow velocity and temperature at all gas vents was measured again. We also conducted a preliminary trial of a tracer gas test to estimate the response time for gas monitoring. The injection point of the tracer gas was determined based on the June survey. In November, we conducted the tracer gas test twice. Temporal variations in gas flow measurements were identified, and the change in gas temperature at night was also measured.

(2) Gas velocity and temperature

The gas velocity and temperature at the exit of the gas vents were measured using an anemometer (Kanomax 6531; detection range of $0.01-30 \mathrm{~m} / \mathrm{s}$ and an accuracy of $\pm 2 \%$ ) and a digital thermometer (Thermo PORT TP-100mR; detection range of -56 to $306^{\circ} \mathrm{C}$ and an accuracy of $\pm 0.1^{\circ} \mathrm{C}$ ). We recorded a 10 -s average gas flow velocity because of the high fluctuations in the flow velocity. Before measuring the velocity and the temperature, we identified the direction of the gas flow at the exit of the gas vents using a smoke tube (GASTEC No. 501). This was very useful due to the difficulty in determining the gas flow direction when the flow velocity was small.

The anemometer and thermometer sensors were inserted into the gas vents as close as possible to ground level (see Figure 4(a)). The altitude of the gas vents was measured by GPS, and photos were taken to record the conditions around these vents, such as the slope of the surrounding area. 
(3) Gas composition

Gas composition was measured using a portable gas analyzer (GA2000 Plus, Geotechnical Instruments). The analyzer was equipped with a pump working at a sampling rate of $300 \mathrm{ml} / \mathrm{min}$. A sampling tube was lowered into a gas vent to a depth of $50 \mathrm{~cm}$ below ground level, and measurements were recorded after $60 \mathrm{~s}$ of sampling. The presence of five different gases $\left(\mathrm{CH}_{4}, \mathrm{CO}_{2}, \mathrm{O}_{2}, \mathrm{CO}, \mathrm{H}_{2} \mathrm{~S}\right)$ were simultaneously detected at ranges of $0 \%-70 \%, 0 \%-40 \%, 0 \%-25 \%, 0-2000 \mathrm{ppm}$, and 0-500 ppm, respectively. The accuracy of the measurements for $\mathrm{CH}_{4}, \mathrm{CO}_{2}$, and $\mathrm{O}_{2}$ were $\pm 0.5 \%$, $\pm 3 \%$, and $\pm 0.1 \%$, respectively. The amount of $\mathrm{N}_{2}$ was determined by the balance of $\mathrm{CH}_{4}, \mathrm{CO}_{2}$, and $\mathrm{O}_{2}$.

\section{(4) Tracer gas test}

Carbon monoxide (CO), which is a minor component in landfill gas, was used as a tracer gas because of the ease with which it can be continuously monitored with a conventional gas meter. CO was detected neither in June (gas composition shown in Figure 7) nor in November. Pure CO gas (100\%) was continuously injected for about two hours, and the output concentration was recorded during the tracer gas injection using a carbon monoxide meter (GCO-2008; SATOSHOUJI INC.), or occasionally by a portable gas analyzer (GA2000 plus, Geotechnical Instruments). The location where CO injection took place and the location of the effluent is described in section 4.1.

\section{Mechanism of aeration}

\subsection{Gas flow rate at passive vents}

The gas flow rates at the gas vents, calculated from the data obtained in June, are plotted in Figure 3. The area of the circle is proportional to the gas flow rate. Flow rate was not determined at several vents, either because they were covered or because of some other reason. Unexpectedly, air flowed in at several gas vents, as shown by the smoke travel path in Figure 4(b). In this context, the gas vents are either called inflow or outflow vents, according to the gas flow direction.

As shown by the contour line in Figure 3, most of the inflow vents were located at low altitudes. According to the theoretical functioning of semi-aerobic landfills, air is drawn in through the leachate collection pipe (see Figure 1). In this landfill, however, gas vents also took in air if they were located near the landfill bottom, even though waste was deposited $15 \mathrm{~m}$ below the exits of inflow vents. In June, we found the top of the leachate pit, into which leachate was discharged from the collection pipe, covered 
with a nonwoven fabric, while it had not been covered in October. Regardless of these different conditions of the leachate collection pit, vents No. 1 and PN1-PN5 functioned as inflow vents during both months.

The air flow rate from the end of the leachate collection pipe (calculated using the average gas velocity and the area of the collection pit) was almost equivalent to that of vent No. 1 in June. The sum of the flow rate was 22.6 (inflow) and 42.6 (outflow) in June, and 53.4 (inflow) and 43.2 (outflow) in October (in $\mathrm{m}^{3} / \mathrm{min}$ ). One third of the inflow rate in October was derived from the gas inflow of the leachate pit. While the smoke exhibited a straight streamline in the outflow vents, there was turbulence in the inflow vents. Inflowing air through gravel deposited around the vent was observed at some of the inflow vents. Therefore, the estimation of the inflow rate is less accurate.

By using an inflow rate of $50 \mathrm{~m}^{3} / \mathrm{min}$ for 7.8 ha, the average air flow rate per hectare is estimated to be $385 \mathrm{~m}^{3} / \mathrm{h}$ in this landfill. As for an aerobic landfill, the average aeration rate in the eight-year in situ aeration project in Germany was calculated to be $325 \mathrm{~m}^{3} / \mathrm{hr}$, using an average aeration flow rate of $1040 \mathrm{~m}^{3} / \mathrm{hr}$ (Ritskowski and Stegmann, 2007) and a total area of 3.2 ha (Heyer et al., 2001). Although the inflow rate is not entirely accurate, and this volume is not used solely for the aeration of waste in this study (this ratio is discussed later in section 4.3), this comparison is helpful in understanding the aeration capacity of a semi-aerobic landfill.

\subsection{Relationship between gas flow rate and gas temperature}

The relationship between the gas flow rate and gas temperature for the outflow vents is shown in Figure 5. The number of gas vents plotted in the figure is 35 and 29 in June and October, respectively, and the ambient temperature is also shown. In both months, a linear correlation was found between these parameters, i.e., as the gas temperature increased, the gas velocity also increased. As indicated by their intersection on the $\mathrm{x}$-axis, this figure supports the assumption that the temperature difference between the waste and the environment is the driving force behind the gas flow.

Therefore, the gas temperature is the most easily measured indicator of the gas flow rate. A higher temperature signals a higher rate of gas flow. If the temperature is equal to that of the environment, either air is drawn into the gas vents or no gas flow exists.

\subsection{Buoyancy effect}

The positive correlation between gas temperature and gas flow rate suggests that air movement is driven by a buoyancy force. Considering a homogeneous block of waste, with the depth and area being designated as $\mathrm{H}$ and $\mathrm{A}$, respectively (Figure 6), 
the buoyancy force working on the air inside the block can be expressed as follows:

$$
F=\varepsilon(\rho(T e)-\rho(T w)) \cdot A \cdot H \cdot g,
$$

where $\varepsilon$ is the porosity of the waste and $\rho$ is the density of the air $\left[\mathrm{kg} / \mathrm{m}^{3}\right]$. Te and Tw are the absolute temperatures of air in the environment and at the waste layer, respectively. Applying Darcy's law and the equation $\mathrm{dP}=\mathrm{F} / \mathrm{A}$, Darcy's velocity (flow rate per unit area $[\mathrm{m} / \mathrm{s}])$ is expressed as follows:

$$
\mathrm{v}=\mathrm{k}_{\mathrm{a}} \cdot \mathrm{dP} / \mathrm{dz}=-\mathrm{k}_{\mathrm{a}} \cdot \mathrm{F} /(\mathrm{A} \cdot \mathrm{H}),
$$

where $\mathrm{k}_{\mathrm{a}}$ is the permeability coefficient $\left[\mathrm{m}^{2} /(\mathrm{s} \cdot \mathrm{Pa})\right]$, and $\mathrm{dP}$ is the pressure difference between the top and the bottom of the block. Using Eq. 1 and the ideal gas law

$$
\rho=\mathrm{M}_{\mathrm{w}} \cdot \mathrm{P}_{0} /(\mathrm{R} \cdot \mathrm{T}),
$$

where $M_{w}$ is the molar mass of air $[\mathrm{kg} / \mathrm{mol}], \mathrm{P}_{0}$ is the standard atmosphere pressure at $0^{\circ} \mathrm{C}, \mathrm{R}$ is the gas constant $[\mathrm{J}(/ \mathrm{mol} \cdot \mathrm{K})]$, and $\mathrm{T}$ is the absolute temperature of air $[\mathrm{K}]$, we can calculate the gas velocity as follows:

$$
\mathrm{v}=\varepsilon \mathrm{k}_{\mathrm{a}} \cdot \mathrm{M}_{\mathrm{w}} \cdot \mathrm{P}_{0} \cdot \mathrm{g} / \mathrm{R}\left(1 / \mathrm{T}_{\mathrm{e}}-1 / \mathrm{T}_{\mathrm{w}}\right)=\varepsilon \cdot \mathrm{k}_{\mathrm{a}} \cdot \mathrm{M}_{\mathrm{w}} \cdot \mathrm{P}_{0} \cdot \mathrm{g} / \mathrm{R}\left(\mathrm{T}_{\mathrm{w}}-\mathrm{T}_{\mathrm{e}}\right) / \mathrm{T}_{\mathrm{e}} \cdot \mathrm{T}_{\mathrm{w}} \cdot
$$

Although this model seems too simple to simulate the gas flow velocity in a landfill, the positive linear correlation shown in Figure 5 supports this hypothesis. Low permeability of waste might be a reason for the low gas flow rate at some vents.

Figure 7 shows the gas composition and velocity at the exit of the outflow gas vents. The residual fraction is the estimated nitrogen. Air is the main component of the gas, and the concentrations of $\mathrm{CH}_{4}$ and $\mathrm{CO}_{2}$ are very low. These low ratios of landfill gas components are reasonable when considering the effluent air supply from the environment stated in section 3.1. Even when landfill gas is generated, its amount is small compared with that of air.

\section{Air flow path in the landfill}

\subsection{Scheme of the tracer test}

To obtain quantitative data on the air flow dynamics in this semi-aerobic landfill, a tracer gas test was conducted on November 15, 2013. The idea was that if air flowed through the waste layer from the leachate collection pipe, it would need a longer travel time to leave the gas vents as compared with just flowing through the pipes and vents.

CO gas was injected into an inflow vent, and the gas concentration was continuously measured at the nearest and other outflow vents. The CO concentration instantly increased from zero to a specific value at the inflow vent; therefore, this was called the "step response test." The tracer gas was injected into either vent No. 1 or PN1. Vent No. 1 was selected because it was the first gas vent on the main leachate 
collection pipe, and it had the largest air inflow rate. The reason for selecting PN1 was its straightforward connection with other vents (see Figure 2). No. 1 was connected to N1, N2, No 2, PS1, and other vents, and air from the end of the leachate collection pipe was mixed with air from those vents. PN1 was directly connected to N1.

Injection of the CO gas into PN1 started at 11:36, and the CO concentration was continuously recorded at N1 using the carbon monoxide meter (GCO-2008). The CO concentration at neighboring gas vents (Nos. 2 and 3, N1-N3, and PN2) was also measured using a portable gas analyzer. Based on a preliminary test conducted in October, the CO gas flow rate was set at $1 \mathrm{~L} / \mathrm{min}$ to keep the gas concentration lower than 1000 ppm, which is the highest detectable concentration for the GCO-2008 meter. Gas injection continued until 13:59 with a total running time of $140 \mathrm{~min}$.

In the same way, CO was injected at 14:29 into vent No. 1, with a gas flow rate of $10 \mathrm{~L} / \mathrm{min}$. The CO concentration was monitored using the GCO-2008 meter at vents Nos. 2 and 3, and the CO concentrations at other gas vents (No. 4 and 5, N1-N3, S6, PS10, and PS11) were also measured two to three times using the GA2000 plus the gas analyzer. CO injection continued for 110 min until 16:30. As shown in Figure 8(b), CO injection into PN1 did not have any influence on the CO concentration at vents Nos.2 and 3.

The input CO concentration was estimated to be 600 ppm at PN1 and 780 ppm at vent No. 1. These figures were calculated from the air velocity and the CO gas flow rate. At PN1, CO concentration was also measured using the GCO-2008 meter, which was lowered into the gas vents to a depth of approximately one meter below ground level to prevent turbulence.

\subsection{Air flow path through the waste layer}

Figure 8(a) shows the CO response at vents Nos. 2 and 3 when CO was injected into vent No. 1. If the air flowing in at vent No. 1 had passed only through the leachate collection pipe and the gas vents, the CO response would have suddenly increased at the travel time of the air flowing through the pipe, and it would have a constant value thereafter. In Figure 8(a), however, after the sudden increase at around 4 minutes of travel time, the CO concentration slowly increased at both vents Nos. 2 and 3. The gradually increasing response curve suggests that there was an air flow passing through the waste layer with a highly variable residence time, ranging from several minutes to hours, which reflect the distribution of the air's travel distance in the waste layer. The CO tracer gas was also detected at vents Nos. 4 and 5, and they showed an increasing trend similar to that observed in Nos. 2 and 3. The detection of CO at vents 
PS10 and PS11 tells us that the leachate collection pipe supplied air through the majority of the interconnected leachate collection pipework.

By integrating all the information obtained in Figure 8(a), we estimated the air flow paths, as shown in Figure 9(a). The air-containing tracer gas injected at vent No. 1 flows in multiple directions through the leachate collection pipe and the gas vents: far downwards and to the sides. If we focus on the CO gas reaching vent No. 2, there are two paths of the tracer gas: the flow passes through the pipe and through the waste, which are denoted in the figure by $\mathrm{P}_{\text {pipe }}$ and $\mathrm{P}_{\text {waste }}$, respectively. $\mathrm{P}_{\text {pipe }}$ has a travel time of around 4 min between vents Nos. 1 and 2. In contrast, $P_{\text {waste }}$ consists of diverse paths in three-dimensional directions, since the flow might occur between any of the segments of the leachate collection pipe where CO gas exists and vent No. 2. The reason why the response curve in Figure 8(a) appears to be increasing after 110 minutes (not having attained a steady state) might be due to the existence of the longer distance flow to vent No. 2.

Figure 8(b) shows the CO response when the tracer gas was injected into PN1. Unlike the response at Nos. 2 and 3, there was no evident $P_{\text {pipe }}$ path between PN1 and N1. We consider this to be due to the clogging of the PN1 vent. The estimated aeration path for the CO injection from PN1 is shown in Figure 9(b).

CO gas was selected for the tracer test for the ease with which it can be continuously monitored. Since CO is not inert and could have been oxidized as it passed through the waste layer during the tracer test, the CO concentration in Figure 8 might have been lower than the actual value.

In Figures 8(a) and 8(b), the lower CO concentration at vent No. 2 as compared with the concentration at vent No. 1, and the lower CO concentration at N1 compared with that at PN1, were obviously influenced by air coming in through the leachate collection pipe, and through from the inlet of vent No. 1, respectively.

\subsection{Aeration of waste}

The tracer test studied the air flow path from one inflow vent to the other outflow vent. In terms of aeration in a semi-aerobic landfill, the ratio of air passing through a waste or pipe network before reaching the gas vents is extremely important. The air flowing out of a vent is a collection of air originating from multiple parts of the leachate collection pipes and inflow vents. If most of the air entering into a landfill travels only through the leachate collection pipe and gas vents, the air will have little effect on the aeration of the waste. In Figure 10, we show a schematic of two paths to a gas vent, in which $f$ is a ratio of air flowing in a pipe, and (1- $f$ ) is the ratio of air 
passing through the waste layer. Using the symbols in the figure, the energy balance produces the following equation.

$$
\mathrm{T} \cong f \mathrm{~T}_{\mathrm{e}}+(1-f) \mathrm{T}_{\mathrm{w}} \text {. }
$$

Waste mass has a large he $t$ capacity, so the temperature of the air passing through the waste layer does not change during the day, i.e., $\mathrm{T}_{\mathrm{w}}$ can be assumed to be constant. The differential form of Eq. (1) is

$$
\mathrm{dT} / \mathrm{dt}=f \mathrm{dTe} / \mathrm{dt}(2)
$$

Therefore, when comparing temperature changes between the outflow gas and the ambient air, the ratio of the two paths can be estimated. For this purpose, a thermometer (CENTER314), connected to a K-type thermocouple (detection range of -200 to $1000^{\circ} \mathrm{C}$ ), was placed at vents No. 2 and No. 3, and N1 at around noon on October 24, and remained there until 11:00 the next day.

Figure 11shows the monitoring results of the temperature of air and gas at vents No. 3 and N1. Data for the first four hours are missing due to problems with placement of the thermometers, and solar radiation caused a sharp increase in the temperature 20 $\mathrm{h}$ after monitoring started. Because the temperature change of the gas is smaller than that of the ambient temperature, different scales were used in Figure 11. As shown by the regression lines, the range of the change in gas temperature was about $20 \%$ (i.e., $f=$ 0.2 ) when compared to the change in the environmental temperature at vent No. 1 . This means that a large portion of the air collected at the gas vents passed through the waste layer, and this ratio was almost the same for vent No. 2. As for N1, the temperature change is very small, which means that the air collected at N1 is mostly passing through the waste layer.

\subsection{Fluctuation of air flow}

The gas flow measured in the waste mass was not stable. There is a negative correlation in the CO concentration between vents Nos. 2 and 3, especially at 60, 72, and 90 minutes, as shown in Figure 8(a). This suggests that the air flow path through the waste randomly changed between neighboring vents, i.e., the gas was occasionally pulled more strongly into one vent, and this situation reversed later. Such gradual changes of the gas flow was observed at other vents as well. For instance, Figure 11 shows consecutive measurements of $10 \mathrm{~s}$ on average. Because the velocity was measured at one vent at a time, each measurement series is independent of the others.

A sudden change in flow direction was observed on October $24^{\text {th }}$. Gas flowed out at N6 $(1.10 \mathrm{~m} / \mathrm{s})$, but on the next day, N6 became the inflow vent $(0.33 \mathrm{~m} / \mathrm{s})$. Rain during the night might have caused this change of direction. 


\section{Conclusion}

398

Our objectives were to clarify the aeration mechanisms and air flow paths occurring in a semi-aerobic landfill. The main findings described in this paper are as follows:

1) Part of the fresh air introduced from the environment into the leachate collection pipe (and from the inflow vents in this landfill) flows through the waste layer toward the gas vents, in addition to passing through the pipes, as suggested by the tracer response curve in section 4.2 .

2) Air flow is driven by a buoyancy force caused by the temperature difference between the waste in the landfill and the ambient temperature, as suggested by the positive correlation between gas velocity and gas temperature in section 3.2.

3) The air collected at gas vents was estimated to flow mostly through the waste layer, as suggested by the smaller decrease of temperature in the gas released from the vent than from the environment, as discussed in section 4.3.

Therefore, the aforementioned assumption made by Matsufuji and Tachifuji (2007) can be revised as follows:

In a semi-aerobic landfill, which has a structure that is open to the environment, the temperature of waste is increased by heat released from aerobic biodegradation. Due to a buoyancy force caused by the temperature difference between the waste and the environment, warmed air and gas in waste layer tend to rise and be vented through the gas vents, and fresh air is drawn from the leachate collection pipe laid at the bottom of landfill.

When considering a semi-aerobic landfill as an aerobic-landfill technology, the most important finding in this study is its aeration ability: there exists a three-dimensional aeration path between the leachate collection pipes in the bottom and the vertically installed vents. Compared with the assumed air flow in Figure 1, in which air is supplied in the vicinity of the leachate collection pipe and gas vents, the waste volume to be aerated is considerably extended. The layout of the pipe network should be designed with respect to the possible air flow paths. Both the leachate collection pipe and the passive gas vents are key elements in a semi-aerobic landfill because the former functions as a conduit supplying air to the landfill, and the latter functions as an exit for the heated air. It is not necessary to connect the gas vents to the leachate collection pipe because the connection only increases the air flow through the pipe, and this has little effect on aeration. 
as waste composition, compaction of the waste, permeability, type and thickness of the cover material, and temperature. This study was carried out in a landfill that has a moderate amount of organic matter and a number of vents located at intervals of 15 to 35 meters, and it was situated in a cool region. The performance of semi-aerobic landfills in other places, such as South Asia for example, is unknown. A high food waste ratio might lead to lower permeability. High ambient temperatures will reduce the temperature difference, and consequently the buoyancy force may become smaller. Even in Japan, waste composition, the layout of pipe networks, and the diameter of pipes are not the same. An on-site study of a full-scale landfill is definitely needed for the assessment of the semi-aerobic landfill's aeration capabilities and its applicability in specific conditions, and to develop better designs of the semi-aerobic landfill.

\section{Acknowledgements}

The authors would like to express their deepest appreciation to the members of Sendai-Kankyo-Kaihatsu Co. Ltd. for their valuable help during our on-site survey.

\section{References}

Heyer, K. -U., Hupe, K., Heerenklage, J., Ritzkowski, M., Dalheimer, F., and Stegmann, R., 1999. Aeration of old landfills as an innovative method of process enhancement and remediation, Sardinia 1999, IV, pp.563-571

Heyer, K. -U., Hupe, K., Ritzkowski, M., and Stegmann, R., 2001. Technical implementation and operation of the low pressure aeration of landfills, Sardinia 2001.

Hirata, O, Matsufuji, Y. Tachifuji, A Yanase, R., 2012. Waste stabilization mechanism by a recirculatory semi-aerobic landfill with the aeration system, J. Material Cycles and Waste Management, 14(1), 47-51.

Kim, H. J., Yoshida, H., and Matsuo, T., 2010. Air and landfill gas movement through passive gas vents installed in closed landfills. Waste Management 30 (3), pp.465-472.

Leikam, K., Heyer, K. -U., and Stegmann, R., 1997. In situ stabilization of completed landfills and old sites, Sardinia 1997, IV. pp.451-462

Matsufuji, Y. and Tachifuji, A., 2007. The history and status of semi-aerobic landfills in Japan and Malaysia. In: Landfill aeration, CISA publisher, pp.109-116.

Matsufuji, Y., History of Semi-aerobic landfill (in Japanese), Mizu (water), 1998, pp.21-26, 65-75. 
Park, S., Kusuda, T., Shimaoka, T., Hanashima, M., 1997. Simulation on behavior of pollutants in semi-aerobic landfill layers (in Japanese), J. of the Japan Society of Waste Management Experts, 8(4), 147-156.

Raga, R., Cossu, R., 2014. Landfill aeration in the framework of a reclamation project in Northern Italy. Waste Management 34, 683-691

Ritzkowski, M. and Stegmann, R., 2007. Biostabilizing a MSW landfill by means of in situ aeration - results of an eight-year project (Stegmann, R. and M.Ritzkowski (ed.) Landfill aeration, CISA, 2007)

Ritzkowski, M. and Stegmann, R., 2012. Landfill aeration worldwide: Concepts, indications and findings, Waste Management, 32, pp.1411-1419

Yanase, R., Matsufuji, Y., Tashiro, T., and Nakatomi, S., 2010. Study on the gas flow of semi-aerobic landfill. Proceedings of the 21th Annual Conference of the Japan Society of Material Cycles and Waste Management Experts, pp.539-540. 


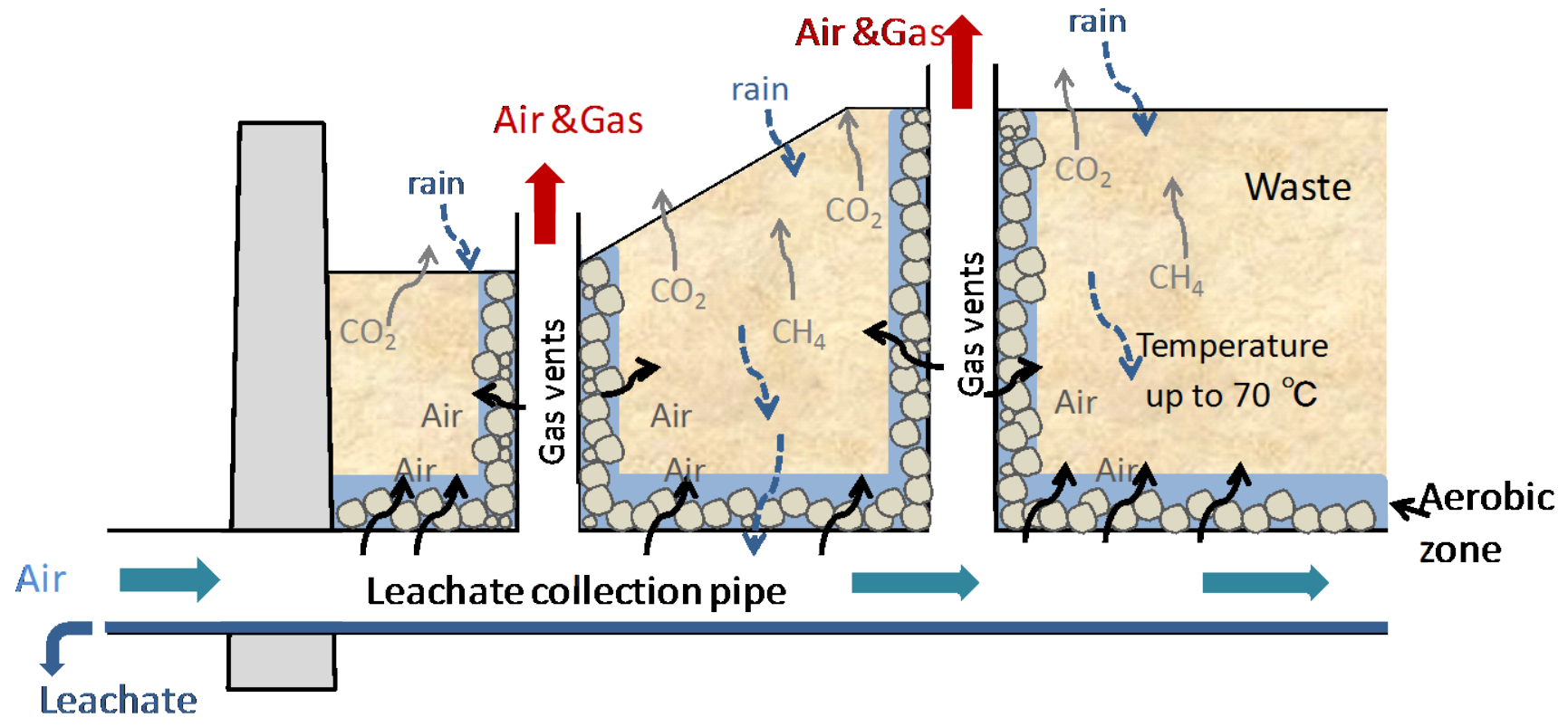

Figure 1 Generally assumed air and gas flow in semi-aerobic landfills

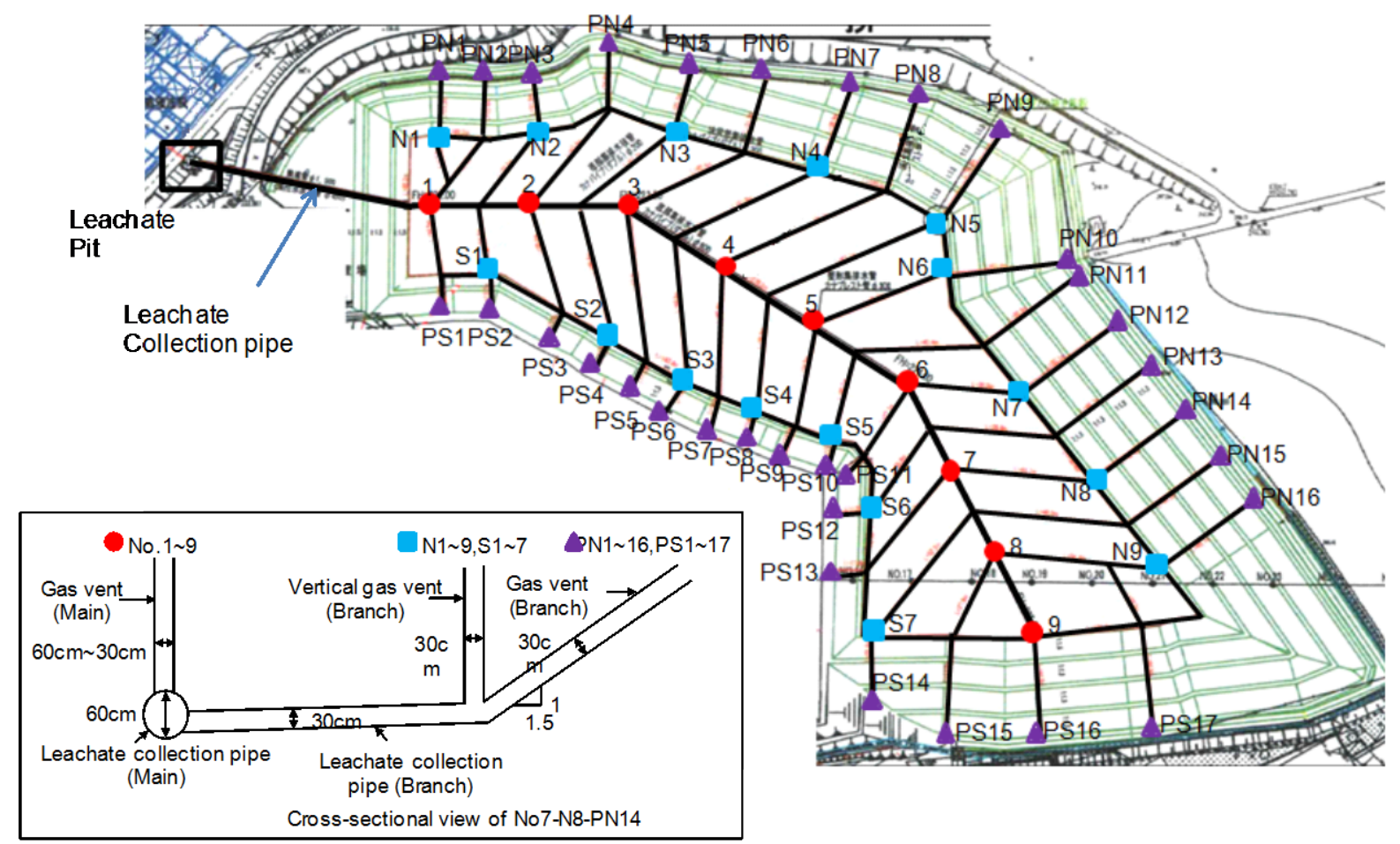

Figure 2 Layout of leachate collection pipes and gas vents in a surveyed semi-aerobic landfill 


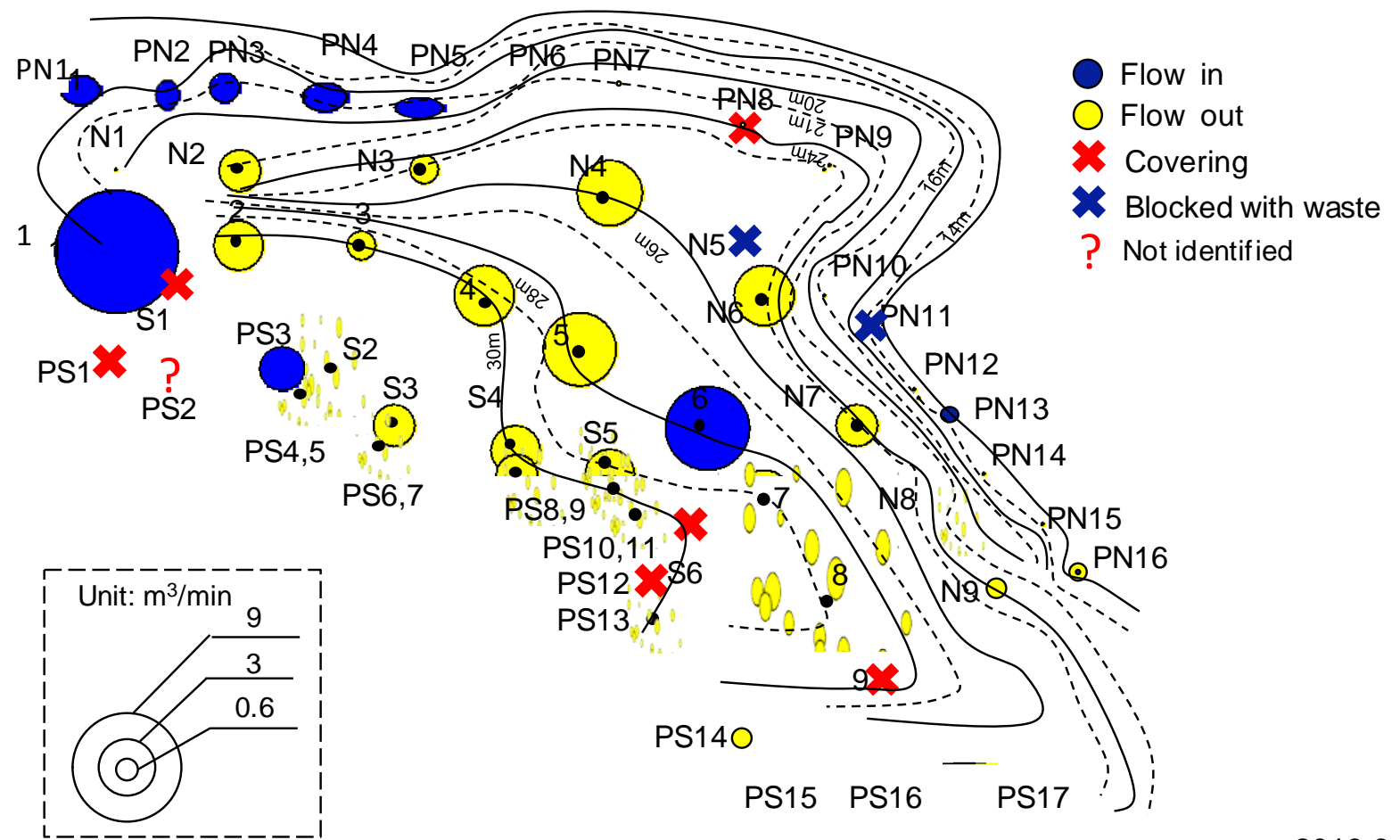

2013.6.19

Figure 3 Gas flow rate at gas vents in June

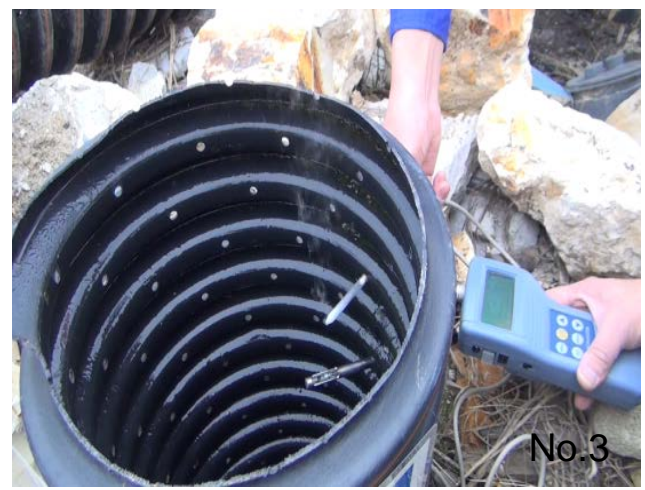

(a) Outflow vent (No.3)

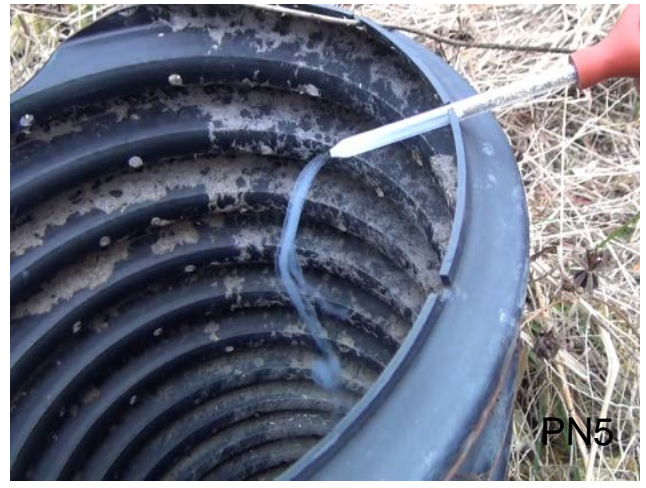

(b) Inflow vent (PN5)

Figure 4 Identified gas flow by smoke tube 


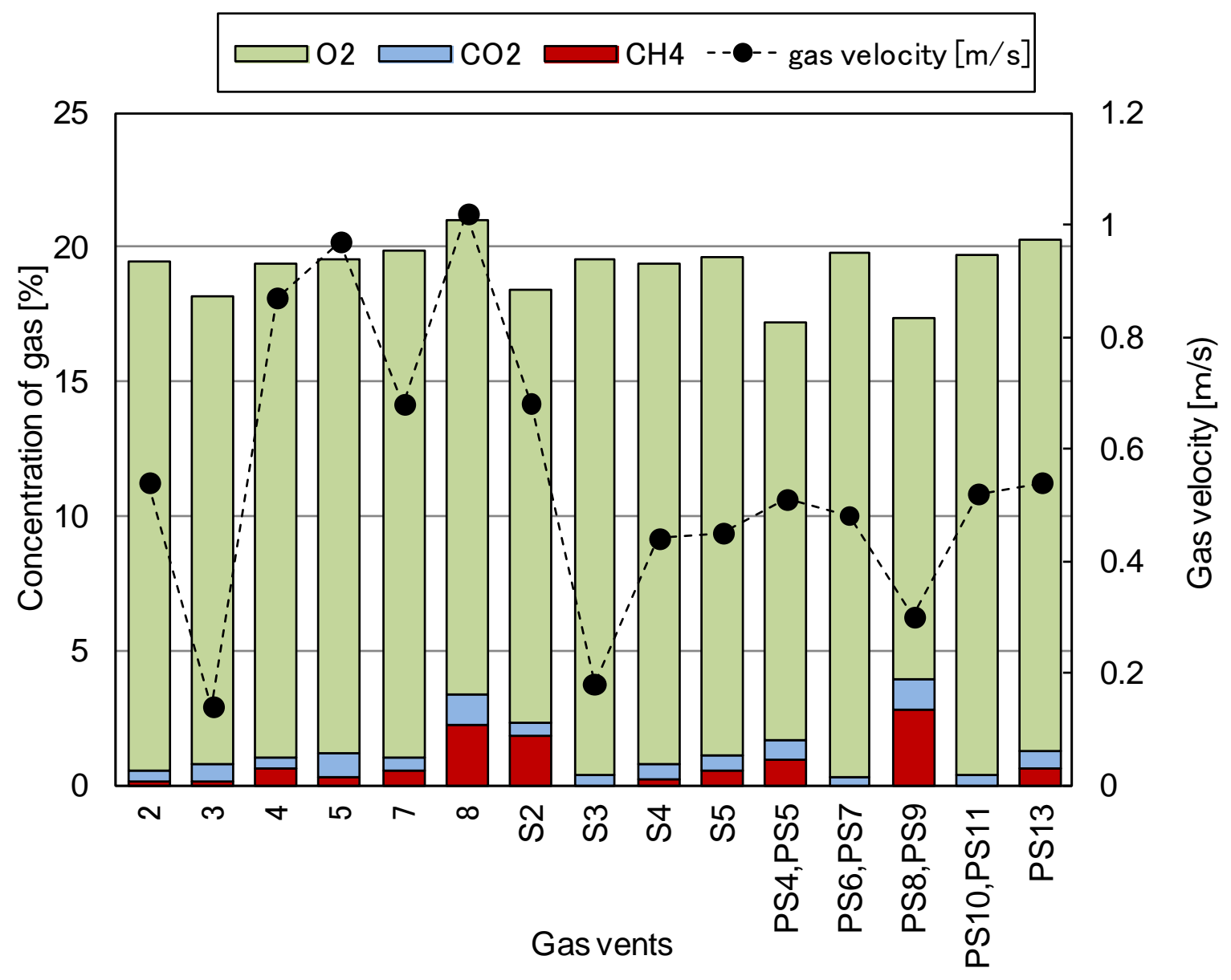

Figure 7 Gas composition at outflow vent 


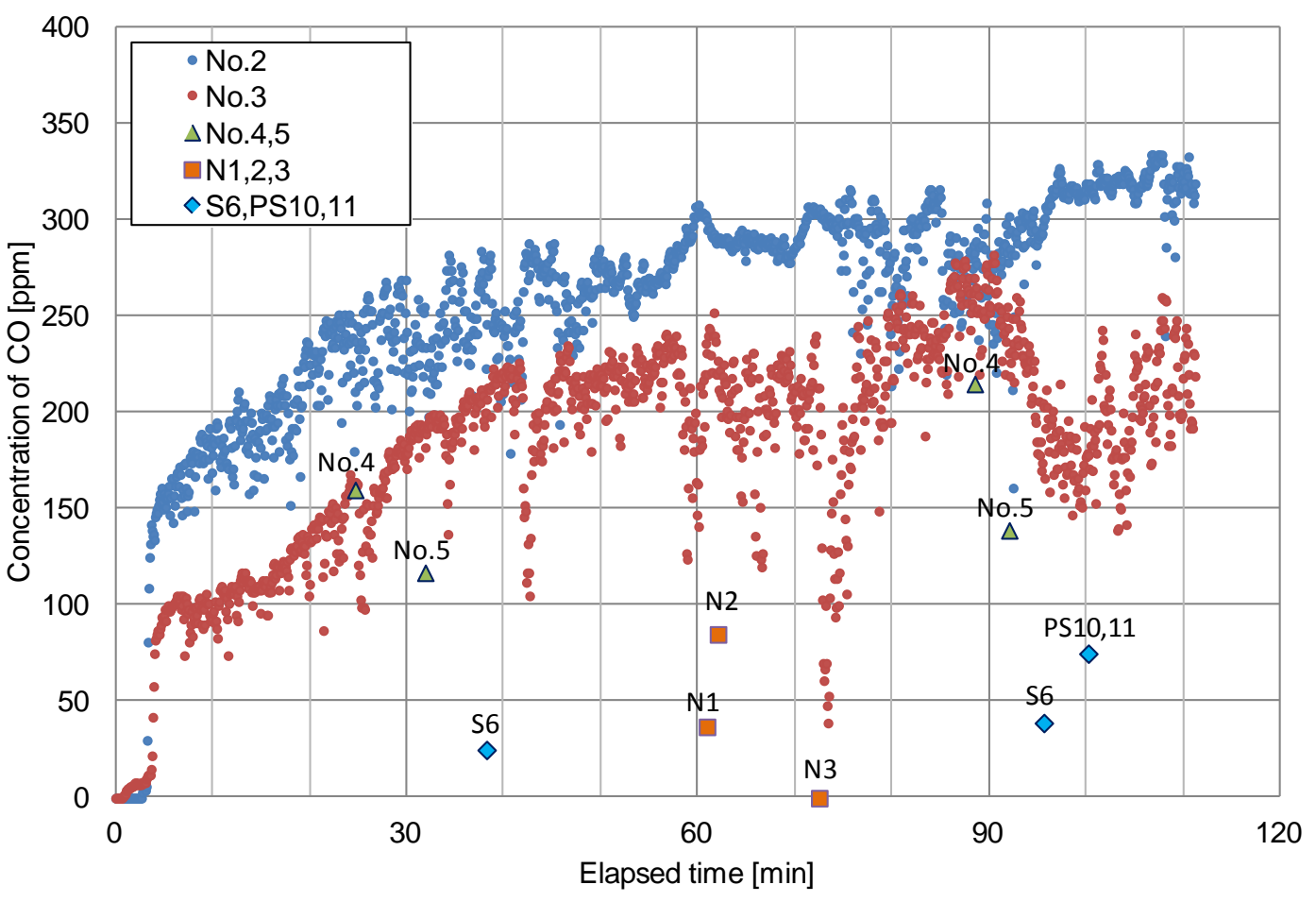

Date: 2013.11 .15

(a) CO injection from No.1 vent (input concentration 780ppm)

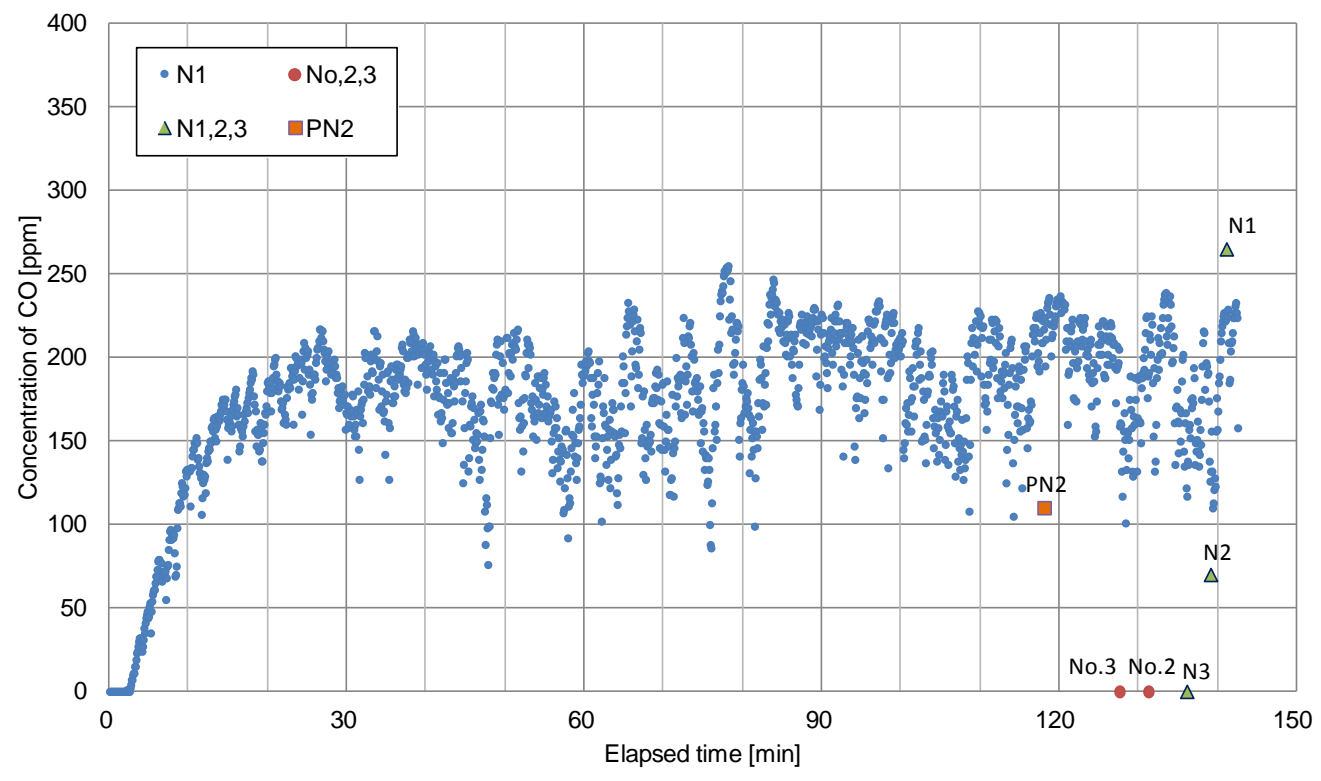

(b) CO injection from PN1 vent (input concentration : 600ppm)

Figure $8 \mathrm{CO}($ Carbon monooxide) gas response at outflow vents 

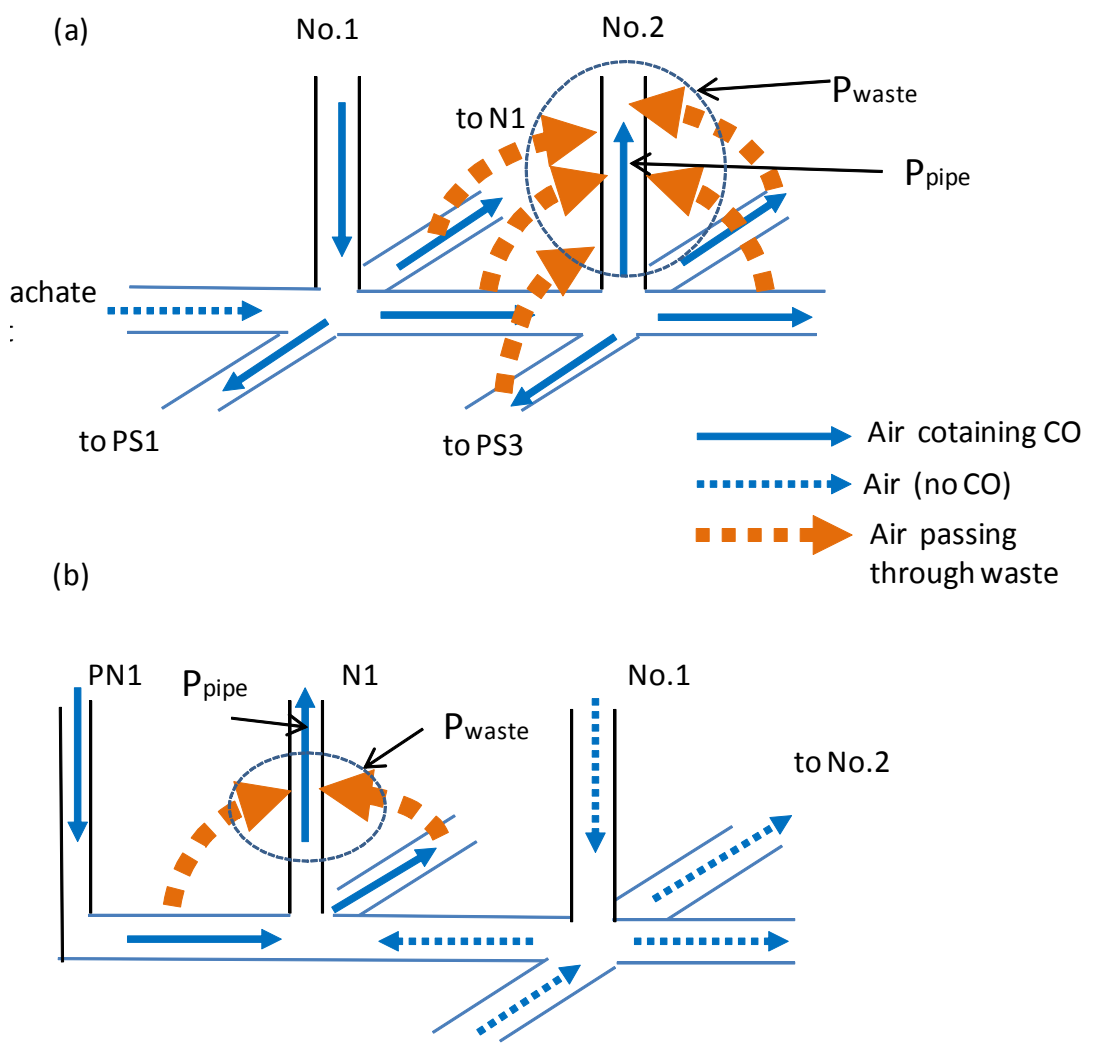

Leachate Pit

Figure 9 Estimated air flow passing through pipes and through waste layer

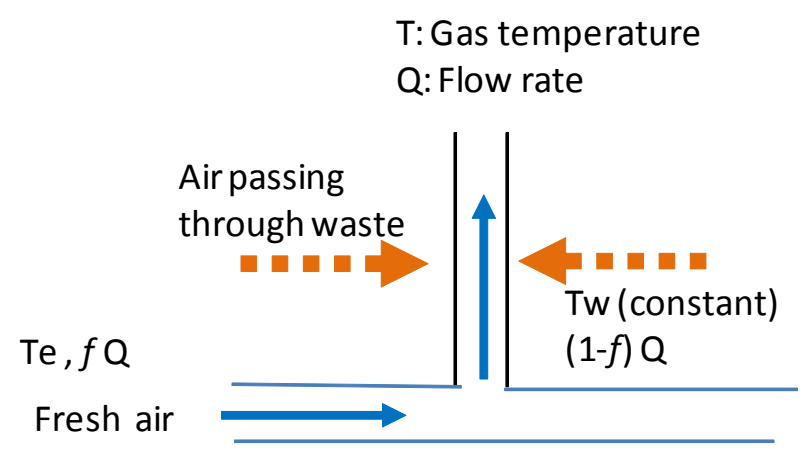

Figure 10 Two paths of air flowing out at outflow vent 

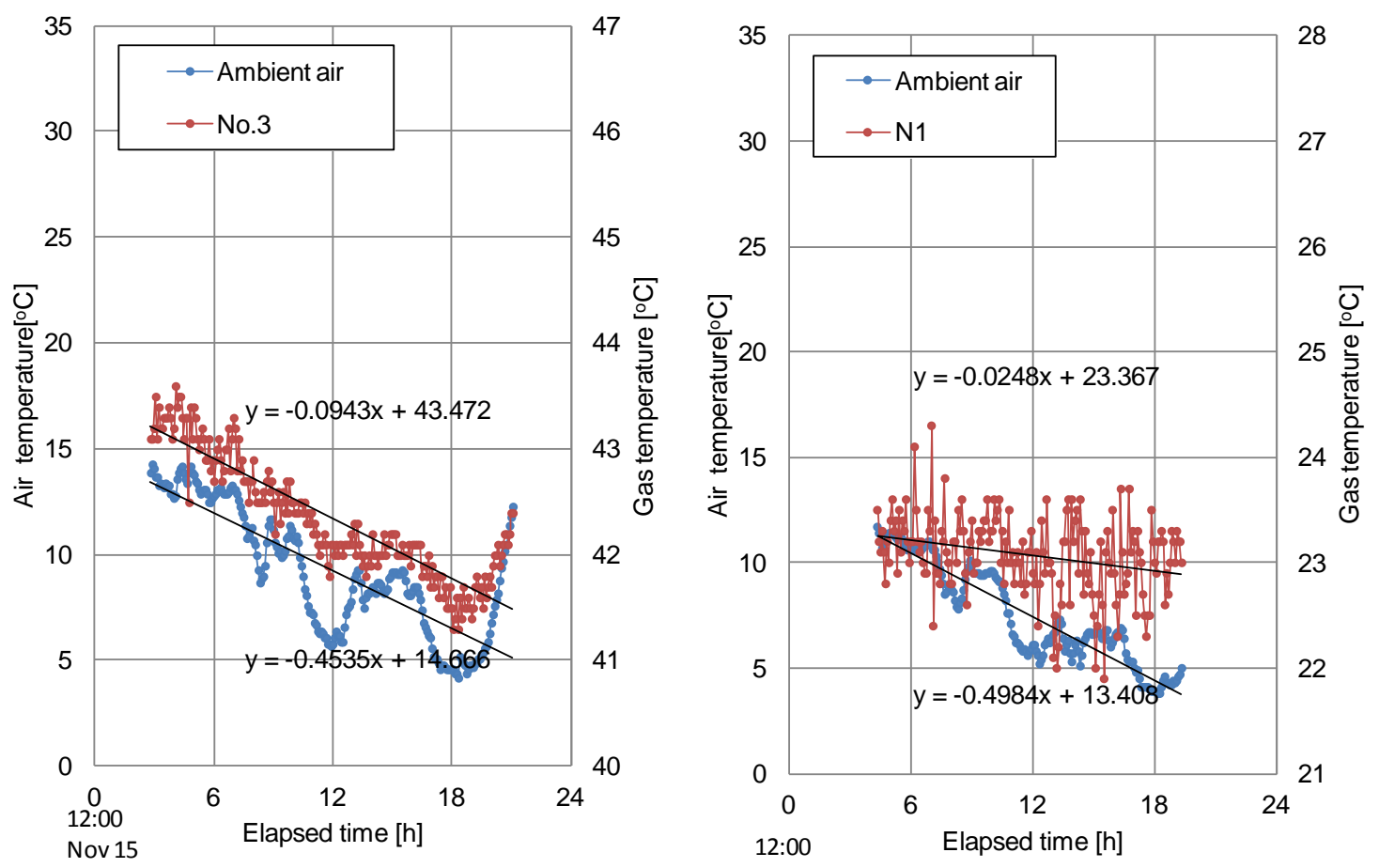

Figure 11 Temperature change of gas and ambient air

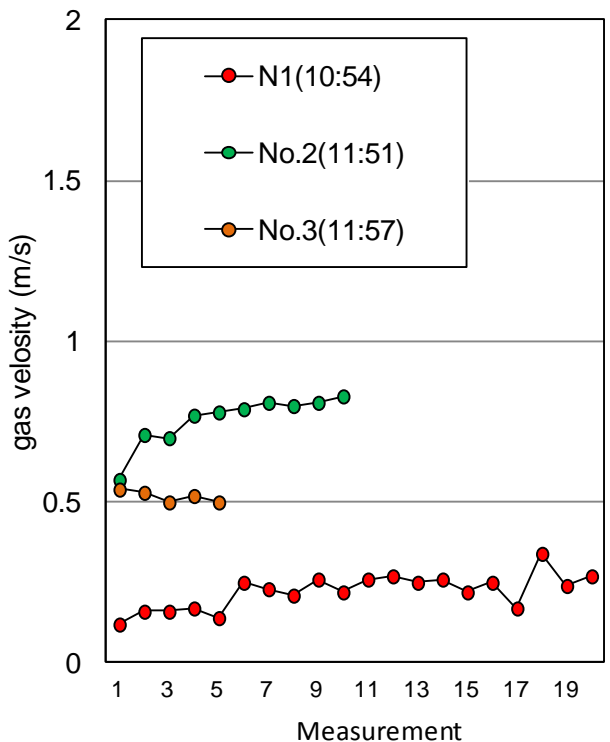

October 25

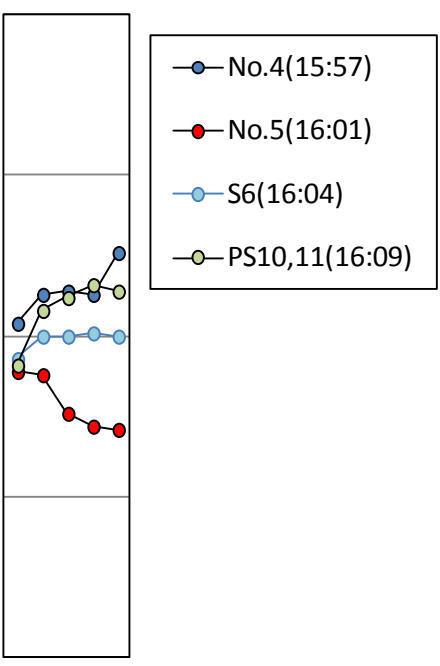

12345

November 15 